\title{
Therapeutic approaches targeting inflammation for diabetes and associated cardiovascular risk
}

\author{
Allison B. Goldfine and Steven E. Shoelson \\ Joslin Diabetes Center and Harvard Medical School, Boston, Massachusetts, USA.
}

\begin{abstract}
Obesity-related sub-acute chronic inflammation has been associated with incident type 2 diabetes and atherosclerotic cardiovascular disease. Inflammation is increasingly considered to be a pathologic mediator of these commonly co-occurring diseases. A growing number of preclinical and clinical studies support the inflammatory hypothesis, but clinical trials to confirm the therapeutic potential to target inflammation to treat or prevent cardiometabolic conditions are still ongoing. There are multiple inflammatory signaling pathways. Regulation is complex, with substantial crosstalk across these multiple pathways. The activity of select pathways may be differentially regulated in different tissues. Pharmacologic approaches to diabetes management may have direct or indirect antiinflammatory effects, the latter potentially attributable to an improved metabolic state. Conversely, some antiinflammatory approaches may affect glucose metabolism and cardiovascular health. To date, clinical trials suggest that targeting one portion of the inflammatory cascade may differentially affect dysglycemia and atherothrombosis. Understanding the underlying biological processes may contribute to the development of safe and effective therapies, although a single approach may not be sufficient for optimal management of both metabolic and athrothrombotic disease states.
\end{abstract}

\section{Introduction}

The obesity epidemic foreshadowed subsequent increases in incident type 2 diabetes (T2D) and atherosclerotic cardiovascular disease (ASCVD), supporting a role for obesity to promote or accelerate pathophysiologic processes underlying and potentially common to both conditions. Several features of obesity are implicated as potential pathologic mediators in cardiometabolic conditions, including tissue triglycerides, oxidative and endoplasmic reticulum stress, mitochondrial dysfunction, and inflammation. Preclinical studies supporting potential etiologic roles for inflammation increased almost exponentially over the last decade, such that inflammation is increasingly considered to be an established mediator. However, clinical studies, which appropriately lag behind the preclinical studies, have yet to confirm inflammation as a pathogenic mediator of insulin resistance, T2D, and ASCVD in humans.

Clinical relationships between T2D and ASCVD are well established. Risk for ASCVD is markedly elevated in patients with T2D compared with those without T2D $(1,2)$. ASCVD typically occurs one to two decades earlier in those with T2D (3), with

Conflict of interest: S.E. Shoelson is a shareholder in Catabasis Pharmaceuticals, which uses novel chemical approaches to target muscular dystrophy. He is also an inventor on the following patents: US Patent 6,468,755 (2002) and US Patent 6,630,312 (2003). A.B. Goldfine receives research support from the American Diabetes Association, the $\mathrm{NIH}$, Cleveland Clinic (with support from Covidien and Ethicon), Xoma, and Diasome. She is a consultant for Kowa Pharmaceuticals, Baronova, the Translational Research Institute for Metabolism and Diabetes at Florida Hospital, and the National Institute of Diabetes and Digestive and Kidney Diseases. She is an inventor on the following patent: US Patent 8524661 (2016). In addition both S.E. Shoelson and A.B. Goldfine are inventors on US Patent 8445467.

Reference information: / Clin Invest. 2017;127(1):83-93. doi:10.1172/JCI88884. greater severity and more diffuse distribution (4). Thus, identification of therapeutic approaches to simultaneously treat or prevent diabetes and atherosclerosis would be of high scientific merit and clinical benefit.

\section{Historical perspectives linking obesity and inflammation}

Epidemiologic associations relating inflammation with obesity and T2D can be traced to the 1950s and 1960s, when circulating concentrations of fibrinogen and other acute-phase reactants were shown to be elevated in these conditions (5-7). Numerous additional epidemiologic studies have extended these early associative findings (8-18). Increased circulating concentrations of markers and mediators of inflammation and acute-phase reactants including fibrinogen, C-reactive protein (CRP), IL-6, plasminogen activator inhibitor 1 (PAI-1), sialic acid, and white cells, among others, all correlate with incident T2D $(8,9)$, as well as other obesity-associated conditions including metabolic syndrome, hypertension, nonalcoholic steatosis, and ASCVD (17, 19-23). Obesity is positively associated with concentrations of inflammatory markers, which are predictive of incident T2D and ASCVD even after controlling for weight and other risk factors $(17,18)$. Furthermore, the magnitude of cardiovascular risk associated with CRP is similar in magnitude to that of traditional risk factors including systolic blood pressure and/or non-HDL cholesterol $(8,24)$. Weight gain and obesity are accompanied by activation of at least two major inflammatory pathways, stress-activated JNK (25) and the transcription factor NF- $\mathrm{KB}$ (26). Epidemiologic, cellular, and molecular data support obesity as a condition of sub-acute chronic inflammation (26), with participation of activated monocytes and tissue macrophages amplifying the inflammatory state via production of proinflammatory cytokines. 


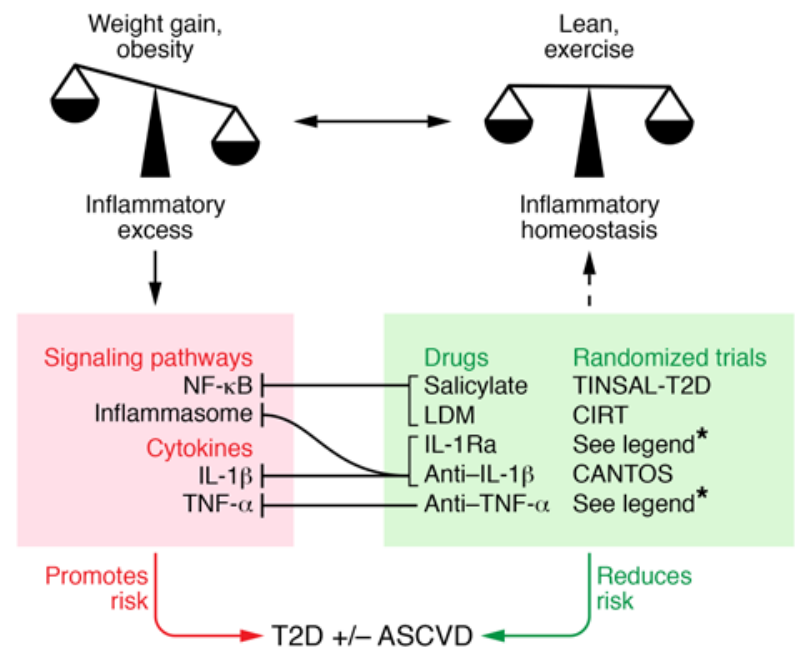

This inflammatory state is thought to reduce insulin responsiveness in insulin-sensitive tissues to promote risk for T2D and ASCVD through actions on cells in the circulation and vasculature $(26,27)$.

The earliest experiments demonstrating that adipose tissuederived proinflammatory cytokines can cause insulin resistance were performed in the 1990s and showed increased TNF- $\alpha$ production in adipose tissue and increased circulating TNF- $\alpha$ in obese rodents (28). Inhibition of TNF- $\alpha$ using neutralizing antibodies improved insulin sensitivity, thereby establishing for the first time in preclinical models a direct role of inflammation in obesityrelated insulin resistance. Markers of inflammation and coagulation are reduced with intensive lifestyle intervention, as seen in the Diabetes Prevention Program (29). Together these findings motivate the investigation of whether inflammation per se can be targeted to reduce disease risk (Figure 1).

\section{Therapeutic approaches with pleiotropic antiinflammatory properties}

Several therapeutic approaches or pharmacologic agents used in current clinical practice are reported to have antiinflammatory properties in addition to their major mechanisms of action. Therapeutic approaches with pleiotropic effects to reduce inflammation include weight-reducing diets and/or lifestyle, pharmacologic or surgical approaches to weight management, statin therapy, and antidiabetic drugs including insulin itself, insulin sensitizers (metformin and thiazolidinediones [TZDs]), incretin modulators, and sodium glucose transport inhibitors, among others.

Weight loss. Lifestyle intervention for weight loss reduces inflammation, assessed as circulating CRP concentrations, in obese persons both with and without T2D (29). However, it is not known whether the reduced inflammation associated with weight loss is responsible for improved glycemic control in T2D and improved cardiovascular and all-cause mortality (30-32). Interestingly, the effects of statins to lower CRP are additive to lifestyle-mediated weight management (33). Weight loss through bariatric surgical approaches also reduces inflammatory markers such as CRP and IL-6 (34). Pharmacologic approaches to manage weight that improve inflammatory markers/mediators include orlistat (35) and naltrexone SR/bupropion (36), which lower CRP,
Figure 1. Clinical trials to target inflammation in T2D and ASCVD. Heightened inflammation that often accompanies obesity or excessive weight gain is a hypothesized mechanism for the associated increase in risk for T2D and ASCVD. Signaling pathways (e.g., NF- $\kappa B$, inflammasome) and specific proinflammatory cytokines (e.g., TNF- $\alpha$, IL-1 $\beta$ ) have been both implicated in these pathologic processes and are potential targets for reversal and risk reduction. Salicylate and low-dose methotrexate (LDM) inhibit NF- $\kappa B$ as a downstream consequence of AMPK activation. IL-1 $\beta$ blockade mediated by IL-1Ra or specific antibodies inhibits IL-1 $\beta$ action and suppresses IL-1 $\beta$ production by dampening its self-induction; the same effect is potentially true for TNF- $\alpha$ blockade. Randomized, placebo controlled, double-masked clinical trials of salsalate (1-7, 128-132, 134, 137), LDM $(8,144)$, IL1Ra $(9-11,178,179,181)$ anti-IL-1 $(181,184,191,192)$, and anti-TNF- $\alpha(12,169)$ are being used to determine whether these antiinflammatory approaches affect disease risk in T2D and ASCVD. Reported randomized trials of 3 months duration or longer are referenced. CANTOS, Canakinumab Anti-inflammatory Thrombosis Outcomes Study; CIRT, Cardiovascular Inflammation Reduction Trial; TINSAL T2D, Targeting Inflammation Using Salsalate for Type 2 Diabetes.

and phentermine/topiramate (37), which raises adiponectin. The diverse molecular targets for these varied approaches suggest that weight loss rather than the molecular target itself contributes importantly to reduce the state of obesity-mediated chronic subacute inflammation. As specific inflammatory proteins altered by these multiple approaches differ, distinct portions of the inflammatory signaling pathways may be differentially affected by these multiple specific therapeutic tactics.

3-Hydroxy-3-methylglutaryl-coenzyme A reductase inhibitors (statins). Reductions in major cardiovascular events are first realized early after statin initiation, which suggests that relevant biologic effects might extend beyond LDL cholesterol lowering (38). While multiple studies demonstrate that statins reduce the inflammatory marker CRP by $13 \%$ to $50 \%$ (39), we don't know whether CRP lowering directly affects the natural history of ASCVD. CRP lowering may be related to statins' ability to downregulate activities of transcription factors associated with inflammation, including NF- $\kappa$ B and HIF-1 $\alpha$ (40). Antiinflammatory properties of statins might also be secondary to reductions in cholesterol, as oxidized cholesterol and cholesterol crystals activate TLRs and the NODlike receptor pyrin-3 (NLRP3) inflammasome, respectively (41, 42). However, CRP lowering with statins is not dose dependent, does not correlate with lipid lowering (39), and is not seen with dramatic cholesterol lowering by proprotein convertase subtilisin/ kexin type 9 (PCSK9) inhibitors (43), suggesting that additional or alternate putative antiinflammatory mechanisms extend beyond cholesterol lowering itself.

The Justification for the Use of Statins in Primary Prevention: An Intervention Trial Evaluating Rosuvastatin (JUPITER) trial (44) intended to test the inflammation hypothesis of ASCVD by comparing rosuvastatin to placebo in 17,802 individuals with elevated CRP $2.0 \mathrm{mg} / \mathrm{l}$ or higher and LDL cholesterol levels below $130 \mathrm{mg} / \mathrm{dl}(3.4 \mathrm{mmol} / \mathrm{l})$ who would not have warranted statin administration according to guidelines at that time. The primary trial endpoint was the composite of myocardial infarction, stroke, arterial revascularization, hospitalization for unstable angina, or death from cardiovascular causes. The trial was stopped early, after a median 1.9 years of follow-up, with a $44 \%$ lower hazard ratio for rosuvastatin. This has been used to support the inflam- 


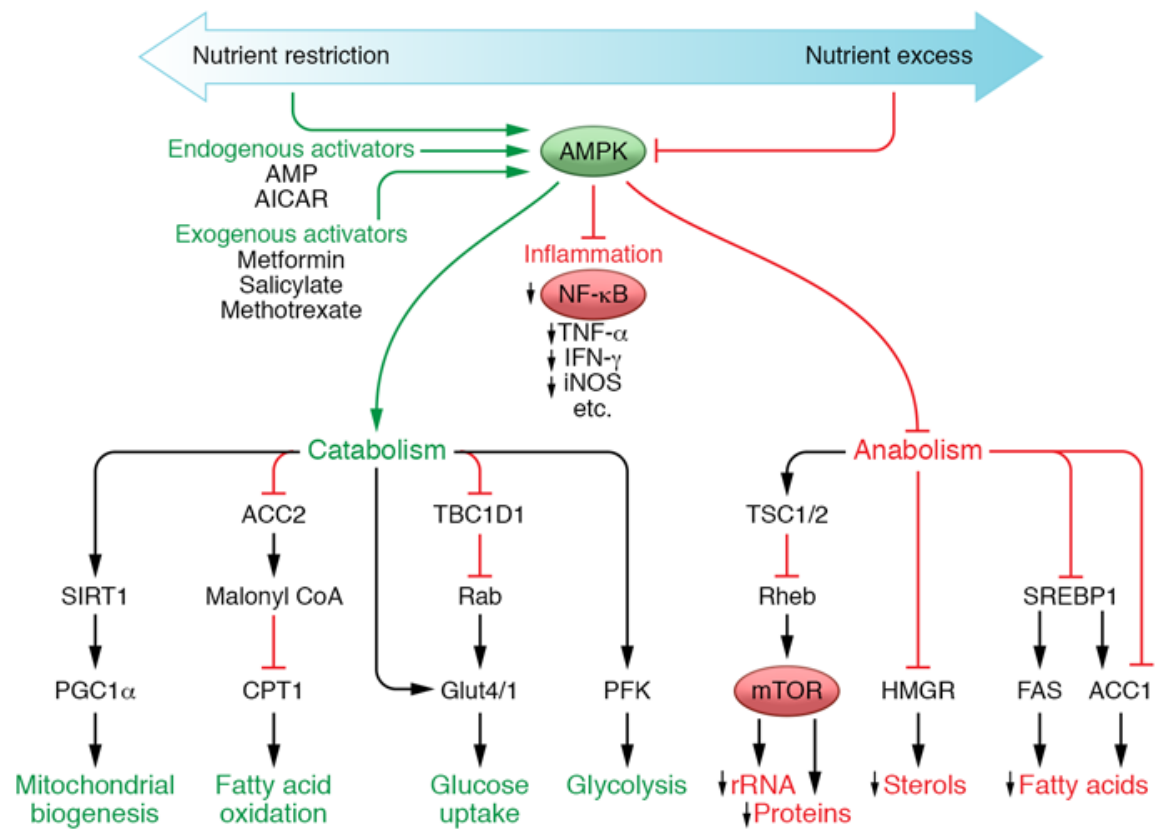

Figure 2. AMPK-regulated metabolism and inflammation. AMPK activation via nutrient restriction or various drugs increases endogenous activators, leading to positive metabolic effects and inhibition of inflammation. AMPK activation promotes (green) nutrient uptake and energy storage while generally suppressing (red) cellular biosynthesis and growth. In cells mediating inflammatory responses, AMPK activation also suppresses NF-kB and synthesis of its targets (red). The antiinflammatory properties of salicylates and methotrexate are mediated, at least in part, through this pathway. matory hypothesis for atherosclerosis. However, while high-sensitivity CRP was reduced 37\%, LDL cholesterol was also reduced by $50 \%$ with rosuvastatin compared with placebo, such that relative contributions of cholesterol and CRP lowering cannot be distinguished. Improvements in ASCVD risk resulting from directly targeting CRP, such as through antibody neutralization or RNA knockdown, have not yet been reported $(45,46)$.

To the extent that statins are antiinflammatory and atherosclerotic risk reduction by statins depends on their antiinflammatory properties, the effects of statins on glycemia are discordant. This was demonstrated in JUPITER, where recipients of rosuvastatin had a higher reported incidence of diabetes (44), a finding that has been born out in additional studies (47). This point is not meant to question the clinical utility or risk/benefit of statins. A meta-analysis of 170,000 persons enrolled in 26 clinical trials showed reductions of $1 \mathrm{mmol} / 1$ (39 mg/dl) in LDL-C during four years of statin use were associated with a $9 \%$ reduction in the risk of death from any cause among patients with diabetes and a $13 \%$ reduction among those without diabetes (48). New-onset diabetes differs in clinical importance compared with a major cardiovascular event (49); in general, statins should be used in patients with T2D (50). Mendelian randomization studies support the idea that diabetes risk may be attributable to inhibition of 3-hydroxy-3-methylglutaryl-coenzyme A, as persons with genetic variants associated with reduced expression of this enzyme and lower LDL cholesterol levels are at increased risk for T2D (51). However, targeting inflammation with statins does not improve glycemia and therefore does not provide a unified antiinflammatory approach for diabetes and ASCVD. This underscores the potential differences in inflammatory pathways that may contribute to and be targeted in ASCVD versus T2D.

\section{Antiinflammatory properties of diabetes drugs}

Many antihyperglycemic drugs are associated with small reductions in inflammatory markers in both circulating cells and the circulation. This appears to be a general feature related to glucose lowering, as the effects can be recapitulated in vitro with changes in ambient glucose. Direct reductions in inflammation appear to be unnecessary for glucose lowering. However, some antihyperglycemic drugs have intrinsic antiinflammatory activities associated with their primary mechanisms of action, including AMPK and PPAR $\gamma$ agonists (52-55). The converse is often not true, as many antiinflammatory drugs do not lower (e.g., COX inhibitors) and may even raise (e.g., corticosteroids) glucose levels.

Insulin. Multiple diabetes therapies reduce markers and potential mediators of inflammation. Insulin itself decreases $\mathrm{NF}-\kappa \mathrm{B}$ activity in peripheral blood mononuclear cells in a manner that is both acute and reversible (56). Insulin administration during acute myocardial infarction will attenuate the rise in CRP, PAI-1, serum amyloid A, and mononuclear cell p47phox, the cytosolic subunit of the multiprotein complex known as NADPH oxidase (57). Hypoglycemia may limit the ability to safely achieve any antiinflammatory effects of insulin; sustained changes have not been documented in comparison to other diabetes therapies (58).

TZDs. TZDs improve insulin sensitivity and reduce hyperglycemia in T2D by binding and activating the nuclear receptor PPAR $\gamma$. Activation of PPAR $\gamma$ induces multiple gene products involved in adipocyte differentiation, lipid and glucose uptake, and fatty acid storage (59). Increased fatty acid uptake into adipose tissue reduces deposition in muscle and liver, where it is deleterious and contributes to insulin resistance. While PPAR $\gamma$ expression is highest in adipocytes, PPAR $\gamma$ expression is also present and increases in cells exposed to adipose tissue lipids, including macrophages and other immune cells, hepatocytes, endothelial cells, and vascular smooth muscle cells $(60,61)$. The antiinflammatory actions of TZDs may be related to transrepression of $\mathrm{NF}-\kappa \mathrm{B}$ and reduced expression of NF- $\kappa \mathrm{B}$ targets (55). Clinically, the ability of TZDs to lower circulating inflammatory proteins such as CRP, monocyte chemoattractant protein 1 (MCP-1, also referred to as CCL2), and MMP-9 is greater than that seen with equivalent glucose lowering induced with the sulfonylurea glimepiride (62). TZDs are effective thera- 
peutically for glucose lowering in T2D and for diabetes prevention $(63,64)$ and partition triglycerides out of the liver in patients with steatosis (65). Associations between TZDs and ASCVD event rates remain controversial (66-68), which may be related to study design, population, or involvement in differential inflammatory pathways that influence diabetes and atherosclerosis.

Metformin. Metformin lowers glucose by decreasing hepatic glucose production and increasing peripheral glucose uptake (69). Its precise molecular mechanism of action remains incompletely understood, but it likely affects mitochondrial proteins to alter cellular energy stores and activate AMPK (70-72). In addition to its clear metabolic effects, AMPK activation is intrinsically antiinflammatory due to its inhibition of NF- $\kappa \mathrm{B}(52-54)$. Metformin attenuates LPS-induced production of TNF- $\alpha$ and IL- 6 in a concentration-dependent manner (73) and reduces TNF- $\alpha$-induced activation of the NF- $\mathrm{KB}$ axis (74). NF- $\kappa \mathrm{B}$ inhibition also reduces IL-1 $\beta$ production (75). Moreover, metformin concordantly reduces circulating inflammatory proteins, including CRP, in patients with or at risk for T2D $(29,76,77)$. The antiinflammatory actions of metformin appear to be independent of glycemia $(58,78,79)$ and are most prominent in immune cells and vascular tissues (53, $54,74,80,81)$. The mechanistic link between metabolism and inflammation may well depend on the balanced activity of the transcription factor HIF- $1 \alpha$ and AMPK regulating oxidative phosphorylation and glycolysis (Figure 2 and reviewed in ref. 52). While novel therapies to target HIFs are under development, there are no human clinical data to date that mechanistically support this target for treating or preventing T2D.

Dipeptidyl peptidase-4 inhibitors. Dipeptidyl peptidase-4 (DPP4 ) is a protease that degrades the incretin hormones glucagon-like peptide 1 (GLP-1) and gastric inhibitory polypeptide, among multiple other peptides. DPP-4 inhibition thereby protects endogenous incretins and prolongs their antihyperglycemic effects. DPP-4 is also known as CD26, a transmembrane glycoprotein expressed on $\mathrm{T}$ lymphocytes, macrophages, and endothelial cells, that regulates the actions of cytokines and chemokines involved in chemotaxis and $\mathrm{T}$ cell activation (82-85). DPP-4 inhibitors suppress the actions of NLRP3 inflammasomes, TLR4, and IL-1 $\beta$ in human macrophages, in part through inhibition of PKC activity (86). Sitagliptin and other DPP-4 inhibitors reduce expression or activity of TNF- $\alpha$, TLR4, TLR2, JNK1, IאB kinase subunit $\beta$ (IKK $\beta$ ), and the chemokine receptor CCR2 $(87,88)$. These antiinflammatory effects may be clinically relevant, as observational studies suggest that DPP-4 inhibitor use in patients with T2D is associated with reduced incidence of rheumatic disease (89). While these drugs can be safely administered in patients with T2D and established (or at high risk for) cardiovascular disease, clinical trials of three distinct DPP-4 inhibitors showed no improvements in cardiovascular outcomes in patients with T2D compared with diabetes regimens that lack incretin modulators (90-92). To the extent that antiinflammatory mechanisms are relevant in metabolic improvement, again there is a lack of established concordant effects of DPP-4 inhibition on glucose lowering and cardiovascular risk reduction.

GLP-1 receptor agonists. The GLP-1 receptor agonist proteins reduce body weight and abdominal adiposity in addition to improving glucose-regulated insulin secretion and glucagon suppression to improve dysglycemia (82). While they are not associated with known receptor-mediated effects, reductions in circulating markers of inflammation can occur with the GLP-1 agonist exenatide even in the absence of substantial weight loss. Markers of inflammation that are reduced include mononuclear cell ROS, NF- $\kappa$ B activity, expression of TNFA, IL1B, JNK1, TLR2, $T L R 4$, and SOC 3 mRNAs, and circulating concentrations of MCP1, MMP-9, serum amyloid A, and IL-6 (93); these largely overlap with the effects of DPP-4 inhibitors, as discussed above $(87,88)$. Several changes reportedly occur within hours after a single drug dose (93). Similar antiinflammatory properties are reported for other GLP-1 receptor agonists, supporting the idea that these are class effects $(82,88)$. Interestingly, major adverse cardiovascular event rates are reduced with liraglutide or semaglutide compared to non-incretin-based diabetes therapies $(94,95)$, although incretin-treated patients also had lower glycated hemoglobin (HbA1C), blood pressure, and body weight than those receiving placebo plus standard care. Improvements in ASCVD outcomes were not seen with the alternative GLP-1 receptor agonist lixisenatide, although severity of patient illness, duration of study and other factors could underlie the apparent differences (96). The contribution of inflammation reduction to diabetes or cardiovascular improvements remains unknown.

Sodium-glucose cotransporter-2 inhibitors. The sodium-glucose cotransporter-2 (SGLT2) inhibitors increase renal excretion of glucose, thereby accounting for their glucose-lowering properties. Non-glycemic benefits include decreases in weight, visceral obesity, blood pressure, arterial stiffness, uric acid concentrations, and albuminurea (97-99). Liver steatosis is reduced in obese rodents $(100,101)$. In humans, circulating biomarkers of inflammation may be improved (102), but data are limited. Activation of AMPK has been reported with canagliflozin, but not with other SGLT2 inhibitors (103). Compared to placebo with standard of care, empagliflozin leads to a $14 \%$ reduction in the composite cardiovascular outcome of cardiovascular death, nonfatal myocardial infarction, or stroke, an effect that is potentially attributable to reductions in heart failure in people with $\mathrm{T} 2 \mathrm{D}$ who are at high risk for cardiovascular events (104). Progression of renal disease is also slowed (105). Effects may be attributable to volume and hemodynamic changes or to improved fuel energetics $(106,107)$. What changes may occur in inflammatory processes in humans resulting from SGLT2 inhibition, and how these may relate to improved mortality, if at all, are unknown.

\section{Pharmacologic approaches that directly target inflammation}

Over recent years a large number of preclinical findings and tantalizing human studies have suggested that inflammation potentially participates in the pathogenesis of T2D and ASCVD (reviewed in refs. 26, 108, 109). Initial enthusiasm around targeting inflammation for these metabolic conditions was limited by concerns over potential immunosuppression. Additional concerns stemmed from the common observation that glucocorticoids, which have strong antiinflammatory properties, promote insulin resistance and diabetes and thus are unlikely agents for disease treatment or prevention, a finding that was thought likely to occur with other direct antiinflammatory approaches. However, many immunomodulation therapies are used safely in autoimmune and rheu- 
matic diseases. Other than glucocorticoids, immunomodulatory therapies are not known to dramatically alter glucose control. In fact, multiple proof-of-concept studies support further evaluation of antiinflammatory approaches to treat cardiometabolic diseases (reviewed in refs. 110-115). Inflammatory signaling is complex and multifaceted. While there are numerous inflammatory inputs and pathways, we do not yet know which one, or which combination of inputs and pathways, leads to distinct cardiometabolic phenotypes. As a result, we also do not know which of the available antiinflammatory strategies, alone or in combination, will have the best therapeutic potential. Activity of select inflammatory pathways among different patients may affect therapeutic responsiveness to specific interventions (116). Additionally, the more recently introduced biological agents are narrowly focused on very specific targets, whereas older antiinflammatory agents such as salicylate or methotrexate may have broader effects (see below).

\section{Small-molecule antiinflammatory drugs}

Salicylates. The vast majority of NSAIDs including ibuprofen and naproxen target the cyclooxygenase enzymes COX1 and COX2. Aspirin and other acetylated salicylates inhibit COX1 and COX2 by covalent transacetylation of active site serine residues of the COX enzymes, which irreversibly blocks the rate-limiting step in prostaglandin synthesis (117). Low-dose aspirin is widely used for anti-thrombosis in primary and secondary CV event prevention. The effects are mediated through COX inhibition in platelets, which is sustained well past the short half-life of aspirin due to the irreversibility of COX acetylation coupled with the longer half-life of platelets and their inability to resynthesize COXs. Low-dose aspirin does not provide sustained COX inhibition in nucleated cells. In contrast, non-acetylated salicylates including salsalate do not inhibit the COX enzymes $(118,119)$ but have nonetheless been used since ancient times to treat pain and inflammation (120). Antiinflammatory and metabolic effects of salicylates are distinct from those of other NSAIDs.

High-dose salicylates are used to treat joint pain, presumably by inhibiting IKK $\beta$ and NF- $\kappa B$ (121-125). Use of salicylate to lower glucose in the treatment of diabetes was first reported in 1876 (126). More recent proof-of-concept studies showed salsalate, a prodrug dimer of salicylate, lowered fasting glucose and triglycerides, increased adiponectin, and improved glucose utilization during euglycemic-hyperinsulinemic clamps in T2D and obese nondiabetic persons (127). Initial observations have been confirmed in multiple cohorts with prediabetes or established disease (128-133). Glycemic efficacy was demonstrated in two multicenter, randomized, placebo-controlled trials in subjects with treated $\mathrm{T} 2 \mathrm{D}$ who had a mean $\mathrm{HbA} 1 \mathrm{C}$ of $7.7 \%$ at trial onset. The first study demonstrated a $0.5 \%$ decrease in $\mathrm{HbA1C}$ relative to placebo over 14 weeks, along with improvements in other markers of glycemic control (133). The next study expanded on these initial observations by using a 48-week follow-up period and a larger patient population (283 participants) (132). Glucose lowering was durable, with a placebo-corrected decrease in HbA1C of $0.4 \%$ despite reductions in use of concomitant medications in salsalate-assigned patients; triglycerides were also lowered. Salsalate lowered white blood cell counts and increased adiponectin, demonstrating antiinflammatory properties at doses used in these investigations, whereas CRP was unchanged. Salsalate was generally well tolerated, but small increases in LDL cholesterol levels and reversible increases in urinary albumin levels were observed in a subset of subjects.

Although salsalate effectively lowers blood glucose, its effects on atherosclerosis are less clear. Salsalate reduces NF- $\kappa$ B activity in endothelial cells and improves endothelial function after four days of use in overweight individuals (134). However, the high dose of salsalate $(4.5 \mathrm{~g} / \mathrm{d})$ used in this study would not be tolerated for extended administration $(127,134)$. In contrast, no effects on flow-mediated dilation were seen in persons with T2D who received salsalate at $3.5 \mathrm{~g} / \mathrm{d}$ over six months (135). It remains unknown whether these differences are due to dosage or study population, or whether the effects of short-term are not sustained, as mixed effects have been reported in additional investigations (131, $136,137)$. To address whether salsalate can reduce progression of non-calcified coronary plaque, a timely question given the inflammatory hypothesis of atherosclerosis, 190 overweight or obese persons with established coronary heart disease taking statin therapy were randomized to salsalate $(3.5 \mathrm{~g} / \mathrm{d})$ or placebo and followed by multidetector computed tomographic angiography over 30 months (138). There was no difference in progression of non-calcified plaque volume between groups, but interpretations of these study results must consider the absence of non-calcified plaque progression in the placebo group, which itself is an important finding for benefits of current multifactorial cardiovascular care.

In terms of molecular mechanism, salicylate inhibits IKK $\beta$ and $\mathrm{NF}-\kappa \mathrm{B}$ but does not bind IKK $\beta$ or other components of the NF- $\mathrm{BB}$ axis directly (121-125). Salicylate is now known to activate AMPK by binding its $\beta 1$ subunit (139), which likely accounts for the metabolic improvements $(127,128,132,133)$. Reduced insulin clearance may also contribute $(127,140,141)$. AMPK activation is clearly accompanied by the inhibition of $\mathrm{NF}-\kappa \mathrm{B}$, although the precise molecular details linking AMPK to IKK and NF- $\mathrm{BB}$ have not been established (52-54, 142, 143). Since salicylate activates AMPK, it is not necessary to invoke NF- $\mathrm{BB}$ inhibition to account for the metabolic improvements.

Low-dose methotrexate. Methotrexate is a disease-modifying antirheumatic drug (DMARD) widely used at low doses to treat rheumatic and psoriatic arthritis, among other conditions. Methotrexate is also in clinical trials for effects in ASCVD and T2D (144). Preclinical support for this approach stems from both basic cell biological and in vivo findings. Methotrexate inhibits the enzyme that converts cellular aminoimidazole carboxamidoribonucleotide (AICAR) into 5-aminoimidazole-4-carboxamide-1- $\beta$-D-ribofuranosyl-5'-monophosphate (FAICAR), leading to an accumulation of AICAR. This has been interpreted to lead either to local adenosine release and activated adenosine signaling (145) or to cell-autonomous AMPK activation (146). Potential cardiometabolic improvements induced by adenosine receptor activation may be mediated through attenuated leukocyte recruitment and adhesion to the vascular endothelium by inhibiting selectin- and integrin-mediated adhesive events, through the reduced production of oxygen radicals and other potentially deleterious mediators from stimulated neutrophils, and through broad effects on macrophage activation (reviewed in ref. 147). Adenosine has also been reported to promote regeneration of pancreatic $\beta$ cells in preclinical models 
$(148,149)$. Alternatively, cellular accumulation of AICAR directly activates AMPK. Consistent with this mechanism, methotrexate promotes glucose uptake and lipid oxidation in skeletal muscle, which is AMPK dependent, and reduces hyperglycemia in rodent models of T2D $(146,150,151)$. Methotrexate has also been shown to inhibit atherogenesis in cholesterol-fed rabbits (152). As noted above, AMPK activation is inherently antiinflammatory and is accompanied by NF- $\mathrm{BB}$ inhibition.

Multiple observational studies of patients with rheumatic diseases suggest lower hazard ratios, ranging from $10 \%$ to $90 \%$, for cardiovascular events or mortality (153-157). Although intriguing, such non-randomized investigations must be interpreted with caution. Related data for glucose lowering are not yet available. Cohort studies are potentially confounded by effects of the comparator drugs used to treat the underlying rheumatic condition for which methotrexate is prescribed, including TNF- $\alpha$ inhibitors, or hydroxycholoroquine or corticosteroids, which themselves may lower or raise glucose levels, respectively. One small cohort study suggests improved glycemia with methotrexate (158). Together these data provided the rationale for the Cardiovascular Inflammation Reduction Trial (CIRT), which evaluates the safety and effectiveness of targeting inflammation with low-dose methotrexate to reduce major adverse cardiovascular events in metabolic syndrome and established coronary heart disease patients and will also evaluate potential for glycemic improvement (144).

\section{Biologics as antiinflammatory drugs}

$T N F-\alpha$ inhibitors. Despite preclinical studies suggesting the participation of TNF- $\alpha$ in the pathophysiology of insulin resistance (28), clinical translation has not been confirmed (159-162). Consistent with a potential role in the pathogenesis of T2D, TNF- $\alpha$ antagonists used to treat conditions such as rheumatoid arthritis (163-167), psoriasis (168), and Crohn's disease (169) have been associated with improved glycemia and decreased incident diabetes. However, since these studies were not randomized and most were not prospective, they must also be interpreted cautiously. Trials with TNF- $\alpha$ antagonists in persons with cardiometabolic risk have thus far involved small numbers of patients exposed for short durations (159-162). While antiinflammatory effects were observed, improved insulin sensitivity or glycemia were not detected, possibly due to insufficient trial duration or power to detect changes. Support for continued investigation in this area is provided by results from a six-month trial of TNF- $\alpha$ inhibition, which reported decreased fasting glucose and increased adiponectin concentrations in obese persons without diabetes (170).

$I L-1 \beta$ antagonists. Although there are 11 members of the IL-1 superfamily, for cardiometabolic indications the field has focused on IL-1 $\beta$ signaling through the type 1 IL-1 receptor (IL-1R1) and inhibition of IL-1 signaling by the endogenous antagonist, IL-1Ra, which competitively binds but does not activate IL-1R1. IL-1R1 acts through MyD88 to activate NF- $\mathrm{BB}$ (171) and other downstream mediators and processes, including iNOS, endothelin-1, endothelial smooth muscle proliferation, activation of macrophages and adhesion molecules, and production of chemokines and cytokines. Many of these are hypothesized to contribute to diabetes and atherothrombosis (reviewed in ref. 172). Similar to TNF- $\alpha$, a feed-forward mechanism drives increased IL-1 $\beta$ production in response to NF- $\mathrm{BB}$ activation. However, the production of active IL-1 $\beta$ involves additional steps, as conversion of IL- $1 \beta$ precursor protein to IL-1 $\beta$ by caspase-1 requires an activated NRLP3 inflammasome (173-175). In chronic inflammatory conditions increased IL-1 $\beta$ secreted by the activated cells leads to an imbalance with the inhibitor IL-1Ra.

Preclinical $(176,177)$ and human studies (178-185) support a potential role for $\mathrm{IL}-1 \beta$ in the pathogenesis of T2D. Improved glycemia and $\beta$ cell secretory function and reduced markers of systemic inflammation were demonstrated in a proof-of-concept trial of 70 patients with T2D randomized to receive daily IL-1Ra (anakinra) or placebo for 13 weeks (180). After anakinra discontinuation participants continued to be followed in a blinded manner for 39 additional weeks, at which time insulin secretion remained improved and inflammation decreased, suggesting that these effects were durable (179). This may be attributable to interruption of the self-propagating cycle of IL-1 auto-induction (186). Anakinra has also been suggested to improve $\beta$ cell secretory function in prediabetes (187), which may prevent or delay the onset of T2D. In addition to anakinra, humanized antibodies against IL-1 $\beta$ are being studied for potential benefits in T2D. In one study, a single dose of gevokizumab reduced $\mathrm{HbA} 1 \mathrm{C}$ by $0.9 \%$ after three months (182). Likewise, 12 weekly injections of the anti-IL-1 $\beta$ antibody LY2189102 improved HbA1C by $0.4 \%$ and also improved fasting and postprandial glycemia and inflammatory biomarkers (185). Similar to the study with anakinra, effects of IL- 1 antagonism were observed after the end of treatment, with a $0.6 \%$ decrease in $\mathrm{HbA1C}$ at week 24.

There is also a rationale for inhibiting IL-1 $\beta$ in ASCVD. In preclinical studies, IL-1 $\beta$ exposure promotes atherosclerotic plaque formation (188), whereas loss of IL-1 function reduces atherosclerotic lesions (189). Human atheroma contain IL-1 $\beta$ mRNA and protein (190), caspase-1, which converts pro-IL-1 $\beta$ to the active form and is overexpressed in human plaque (191), and cholesterol crystals, which activate the NLRP3 inflammasome $(41,42)$, thereby activating caspase- 1 to trigger IL- $1 \beta$ production and the proinflammatory response. In one study, the IL-1 $\beta$ monocolonal antibody canakinumab reduced the inflammatory proteins CRP, IL-6, and fibrinogen in persons with T2D and high cardiovascular risk (192). However, HbA1C, glucose, and insulin were unchanged at four months. The much larger Canakinumab Anti-Inflammatory Thrombosis Outcome Study (CANTOS) will provide further insight into the effects of canakinumab on both cardiovascular event rates and glycemia (193).

\section{Other antiinflammatory approaches in cardiometabolic disease}

Other antiinflammatory approaches are under investigation. Increases in the numbers of macrophages and other immune cells in adipose tissue that accompany the development of obesity in rodents and humans may account for the local inflammation and systemic insulin resistance associated with the induction of obesity $(111,194)$. Reduced leukocyte recruitment may therefore diminish adipose tissue inflammation to potentially improve insulin resistance. Chemoattractants including leukotrienes (lipids) and chemokines (polypeptides) thus provide additional potential antiinflammatory targets in cardiometabolic conditions. 
Leukotrienes are highly potent chemoattractants produced at sites of injury and inflammation for the recruitment of neutrophils and other myeloid cells $(195,196)$. Leukotriene biosynthesis occurs through the conversion of arachidonic acid, first by the actions of 5-lipoxygenase (5-LO) and 5-LO-activating protein (FLAP) to form leukotriene A4 (LTA4), at which point the synthetic pathway bifurcates. Depending on the setting, LTA4 is converted either by LTA4 hydrolase (LTA4H) into the highly active leukotriene LTB4, or by LTC4 synthase into the cysteinyl leukotrienes. LTB 4 binds and signals through the B leukotriene receptor BLT1, whereas cysteinyl leukotrienes LTC4 and LTD4 bind cysteinyl leukotriene receptor subtypes 1 and 2 . Studies to determine whether antagonists of the enzymes for leukotriene production (5-LO, FLAP and LTA4H) $(197,198)$ or receptor binding (BLT1) have cardiometabolic outcome benefits are ongoing and results have not yet been reported.

Similarly, disruption of cytokine/receptor interactions might be used to decrease obesity-induced inflammation and insulin resistance, although the abundance of chemokines and chemokine receptors makes this a potentially difficult approach. The most studied cytokine/receptor pair in terms of preclinical cardiometabolic improvements are CCL2 and its receptor, CCR2, which are involved in the recruitment of monocytes to sites of inflammation (199-201). However, the results of clinical studies with CCR2 antagonists have not been reported. Although COX2 inhibition may reduce adipose tissue inflammation and improve insulin resistance in fructose-fed rat models of disease $(202,203)$, the use of COX inhibitors has been associated with an increased cardiovascular risk (204-206), which may limit this approach. Novel approaches to evaluate antiinflammatory diets $(207,208)$ and modulate an individual's microbiome $(209,210)$ are also under study. Some of these or other antiinflammatory approaches may provide future therapeutic options.

\section{Summary}

In summary, multiple diseases may be caused or exacerbated by pathologic activation of the immune system. Some of these inflam- matory pathways impact glucose metabolism and cardiovascular health. Likewise, many antidiabetic agents have antiinflammatory properties, some of which are direct effects while others may be secondary to improved metabolic state. Novel therapeutic approaches targeting inflammation to treat or prevent diabetes and ASCVD may be developed. Indeed, a large body of tantalizing data supports ongoing investigations of multiple approaches to target inflammation to improve cardiometabolic health. However, strong clinical data supporting approaches to simultaneously target diabetes and ASCVD do not yet exist, which also raises the question of the validity of the yet unproven hypothesis that chronic subacute inflammation is the commonality between these frequently co-occurring conditions. Clinical trials employing multiple approaches to test the inflammatory hypothesis are ongoing; however, as specific molecular inflammatory pathways involved in diabetes and atherosclerosis may differ, the potential therapeutic approaches to these conditions may likewise be different even within the broader context of antiinflammatory therapy. A nuanced understanding of the underlying biological processes may contribute to the development of safe and effective therapies, although a single approach may not be sufficient for optimal management of both metabolic and atherothrombotic disease states.

\section{Acknowledgments}

This work was supported by NIH grants DK045943, DK051729, DK073547, DK090792, DK095327, DK108936 and HL133329 (to SES); DK074556, and HL083813 (to ABG and SES); and HL101422 (ABG); American Diabetes Association grants 1-06-RA-126, 7-04MN-47, 7-06-CVD-31, 7-08-MN-55, 7-09-CVD-08, 1-12-CT-71, and 7-12-MN-77 (to SES) and 7-13-CE-17 (to ABG); and the Helen and Morton Adler Chair (to SES). We gratefully acknowledge use of core facilities of the Joslin Diabetes Center, which are supported by NIH P3ODK036836.

Address correspondence to: Allison B. Goldfine, Joslin Diabetes Center, One Joslin Place, Boston Massachusetts 02215, USA. Phone: 617.309.2643; E-mail: allison.goldfine@joslin.harvard.edu.
1. Gregg EW, et al. Changes in diabetes-related complications in the United States, 1990-2010. N Engl J Med. 2014;370(16):1514-1523.

2. Haffner SM, Lehto S, Rönnemaa T, Pyörälä K, Laakso M. Mortality from coronary heart disease in subjects with type 2 diabetes and in nondiabetic subjects with and without prior myocardial infarction. N Engl J Med.1998;339(4):229-234.

3. Booth GL, Kapral MK, Fung K, Tu JV. Relation between age and cardiovascular disease in men and women with diabetes compared with non-diabetic people: a population-based retrospective cohort study. Lancet. 2006;368(9529):29-36.

4. Beckman JA, Paneni F, Cosentino F, Creager MA. Diabetes and vascular disease: pathophysiology, clinical consequences, and medical therapy: part II. Eur Heart J. 2013;34(31):2444-2452.

5. Ogston D, McAndrew GM. Fibrinolysis in obesity. Lancet. 1964;2(7371):1205-1207.

6. Grace CS, Goldrick RB. Fibrinolysis and body bulid. Interrelationships between blood fibrinolysis, body composition and parameters of lipid and carbohydrate metabolism. JAtheroscler Res. 1968;8(4):705-719.

7. Fearnley GR, Vincent CT, Chakrabarti R. Reduction of blood fibrinolytic activity in diabetes mellitus by insulin. Lancet. 1959;2(7111):1067.

8. Emerging Risk Factors Collaboration, et al. $\mathrm{C}$-reactive protein concentration and risk of coronary heart disease, stroke, and mortality: an individual participant meta-analysis. Lancet. 2010;375(9709):132-140.

9. Ridker PM, Cushman M, Stampfer MJ, Tracy $\mathrm{RP}$, Hennekens CH. Inflammation, aspirin, and the risk of cardiovascular disease in apparently healthy men. NEngl JMed.1997;336(14):973-979.

10. Barzilay JI, et al. The relation of markers of inflammation to the development of glucose disorders in the elderly: the Cardiovascular Health Study. Diabetes. 2001;50(10):2384-2389.

11. Duncan BB, et al. Low-grade systemic inflammation and the development of type 2 diabetes: the atherosclerosis risk in communities study. Diabetes. 2003;52(7):1799-1805.
12. Festa A, D'Agostino R, Tracy RP, Haffner SM, Insulin Resistance Atherosclerosis Study. Elevated levels of acute-phase proteins and plasminogen activator inhibitor-1 predict the development of type 2 diabetes: the insulin resistance atherosclerosis study. Diabetes. 2002;51(4):1131-1137.

13. Ford ES. Leukocyte count, erythrocyte sedimentation rate, and diabetes incidence in a national sample of US adults. Am J Epidemiol. 2002;155(1):57-64.

14. Freeman DJ, et al. C-reactive protein is an independent predictor of risk for the development of diabetes in the West of Scotland Coronary Prevention Study. Diabetes. 2002;51(5):1596-1600.

15. Nakanishi N, Yoshida H, Matsuo Y, Suzuki K, Tatara $\mathrm{K}$. White blood-cell count and the risk of impaired fasting glucose or Type II diabetes in middle-aged Japanese men. Diabetologia. 2002;45(1):42-48.

16. Spranger J, et al. Inflammatory cytokines and the risk to develop type 2 diabetes: results of the prospective population-based European Prospective Investigation into Cancer and 
Nutrition (EPIC)-Potsdam Study. Diabetes. 2003;52(3):812-817.

17. Pradhan AD, Manson JE, Rifai N, Buring JE, Ridker PM. C-reactive protein, interleukin 6, and risk of developing type 2 diabetes mellitus. JAMA. 2001;286(3):327-334.

18. Thorand B, et al. C-reactive protein as a predictor for incident diabetes mellitus among middle-aged men: results from the MONICA Augsburg cohort study, 1984-1998. Arch Intern Med. 2003;163(1):93-99.

19. Rana JS, et al. Differential leucocyte count and the risk of future coronary artery disease in healthy men and women: the EPIC-Norfolk Prospective Population Study. J Intern Med. 2007;262(6):678-689.

20. Ridker PM, Buring JE, Cook NR, Rifai N. C-reactive protein, the metabolic syndrome, and risk of incident cardiovascular events: an 8-year follow-up of 14719 initially healthy American women. Circulation. 2003;107(3):391-397.

21. Sesso HD, Buring JE, Rifai N, Blake GJ, Gaziano JM, Ridker PM. C-reactive protein and the risk of developing hypertension. JAMA. 2003;290(22):2945-2951.

22. Visser M, Bouter LM, McQuillan GM, Wener $\mathrm{MH}$, Harris TB. Elevated C-reactive protein levels in overweight and obese adults. JAMA. 1999;282(22):2131-2135.

23. Vozarova B, Weyer C, Lindsay RS, Pratley RE, Bogardus C, Tataranni PA. High white blood cell count is associated with a worsening of insulin sensitivity and predicts the development of type 2 diabetes. Diabetes. 2002;51(2):455-461.

24. Emerging Risk Factors Collaboration, et al. C-reactive protein, fibrinogen, and cardiovascular disease prediction. $N$ Engl J Med. 2012;367(14):1310-1320.

25. Hirosumi J, et al. A central role for JNK in obesity and insulin resistance. Nature. 2002;420(6913):333-336.

26. Shoelson SE, Lee J, Goldfine AB. Inflammation and insulin resistance. JClin Invest. 2006;116(7):1793-1801.

27. Fujisaka S, et al. Regulatory mechanisms for adipose tissue M1 and M2 macrophages in diet-induced obese mice. Diabetes. 2009;58(11):2574-2582.

28. Hotamisligil GS, Shargill NS, Spiegelman BM. Adipose expression of tumor necrosis factor-alpha: direct role in obesity-linked insulin resistance. Science. 1993;259(5091):87-91.

29. Haffner S, et al. Intensive lifestyle intervention or metformin on inflammation and coagulation in participants with impaired glucose tolerance. Diabetes. 2005;54(5):1566-1572.

30. Chow LS, et al. Twenty year fitness trends in young adults and incidence of prediabetes and diabetes: the CARDIA study. Diabetologia. 2016;59(8):1659-1665.

31. Li G, et al. Cardiovascular mortality, all-cause mortality, and diabetes incidence after lifestyle intervention for people with impaired glucose tolerance in the Da Qing Diabetes Prevention Study: a 23-year follow-up study. Lancet Diabetes Endocrinol. 2014;2(6):474-480.

32. Knowler WC, et al. Reduction in the incidence of type 2 diabetes with lifestyle intervention or metformin. N EnglJMed. 2002;346(6):393-403.
33. Belalcazar LM, et al. Lifestyle intervention and/ or statins for the reduction of C-reactive protein in type 2 diabetes: from the look AHEAD study. Obesity (Silver Spring). 2013;21(5):944-950.

34. Rao SR. Inflammatory markers and bariatric surgery: a meta-analysis. Inflamm Res. 2012;61(8):789-807.

35. Derosa G, Maffioli P, Sahebkar A. Improvement of plasma adiponectin, leptin and C-reactive protein concentrations by orlistat: a systematic review and meta-analysis. Br JClin Pharmacol. 2016;81(5):819-834.

36. Apovian CM, et al. A randomized, phase 3 trial of naltrexone SR/bupropion SR on weight and obesity-related risk factors (COR-II). Obesity (Silver Spring). 2013;21(5):935-943.

37. Garvey WT, et al. Prevention of type 2 diabetes in subjects with prediabetes and metabolic syndrome treated with phentermine and topiramate extended release. Diabetes Care. 2014;37(4):912-921.

38. Ridker PM, et al. Inflammation, pravastatin, and the risk of coronary events after myocardial infarction in patients with average cholesterol levels. Cholesterol and Recurrent Events (CARE) Investigators. Circulation. 1998;98(9):839-844.

39. Balk EM, et al. Effects of statins on nonlipid serum markers associated with cardiovascular disease: a systematic review. Ann Intern Med. 2003;139(8):670-682.

40. Castrillo A, Tontonoz P. Nuclear receptors in macrophage biology: at the crossroads of lipid metabolism and inflammation. Annu Rev Cell Dev Biol. 2004;20:455-480.

41. Duewell P, et al. NLRP3 inflammasomes are required for atherogenesis and activated by cholesterol crystals. Nature. 2010;464(7293):1357-1361.

42. Rajamäki K, et al. Cholesterol crystals activate the NLRP3 inflammasome in human macrophages: a novel link between cholesterol metabolism and inflammation. PLoS One. 2010;5(7):e11765.

43. Sahebkar A, et al. Effect of monoclonal antibodies to PCSK9 on high-sensitivity C-reactive protein levels: a meta-analysis of 16 randomized controlled treatment arms. Br JClin Pharmacol. 2016;81(6):1175-1190.

44. Ridker PM, et al. Rosuvastatin to prevent vascular events in men and women with elevated C-reactive protein. NEnglJ Med.2008;359(21):2195-2207.

45. Warren MS, Hughes SG, Singleton W, Yamashita M, Genovese MC. Results of a proof of concept, double-blind, randomized trial of a second generation antisense oligonucleotide targeting high-sensitivity C-reactive protein (hs-CRP) in rheumatoid arthritis. Arthritis Res Ther. 2015;17:80.

46. Noveck R, et al. Effects of an antisense oligonucleotide inhibitor of $\mathrm{C}$-reactive protein synthesis on the endotoxin challenge response in healthy human male volunteers. J Am Heart Assoc. 2014;3(4): e001084.

47. Rajpathak SN, Kumbhani DJ, Crandall J, Barzilai $\mathrm{N}$, Alderman M, Ridker PM. Statin therapy and risk of developing type 2 diabetes: a meta-analysis. Diabetes Care. 2009;32(10):1924-1929.

48. Cholesterol Treatment Trialists' (CTT) Collaboration, et al. Efficacy and safety of more intensive lowering of LDL cholesterol: a meta-analysis of data from 170,000 participants in 26 randomised trials. Lancet. 2010;376(9753):1670-1681.
49. Goldfine AB. Statins: is it really time to reassess benefits and risks? N Engl JMed. 2012;366(19):1752-1755.

50. American Diabetes Association. Cardiovascular disease and risk management. Diabetes Care. 2016;39(suppl 1): S60-S71.

51. Swerdlow DI, et al. HMG-coenzyme A reductase inhibition, type 2 diabetes, and bodyweight: evidence from genetic analysis and randomised trials. Lancet. 2015;385(9965):351-361.

52. O'Neill LA, Hardie DG. Metabolism of inflammation limited by AMPK and pseudo-starvation. Nature. 2013;493(7432):346-355.

53. Hattori Y, Suzuki K, Hattori S, Kasai K. Metformin inhibits cytokine-induced nuclear factor kappaB activation via AMP-activated protein kinase activation in vascular endothelial cells. Hypertension. 2006;47(6):1183-1188.

54. Isoda K, et al. Metformin inhibits proinflammatory responses and nuclear factor-kappaB in human vascular wall cells. Arterioscler Thromb Vasc Biol. 2006;26(3):611-617.

55. Pascual G, et al. A SUMOylation-dependent pathway mediates transrepression of inflammatory response genes by PPAR- $\gamma$. Nature. 2005;437(7059):759-763.

56. Dandona $P$, et al. Insulin inhibits intranuclear nuclear factor kappaB and stimulates IкB in mononuclear cells in obese subjects: evidence for an anti-inflammatory effect? J Clin Endocrinol Metab. 2001;86(7):3257-3265.

57. Chaudhuri A, et al. Anti-inflammatory and profibrinolytic effect of insulin in acute ST-segment-elevation myocardial infarction. Circulation. 2004;109(7):849-854.

58. Pradhan AD, Everett BM, Cook NR, Rifai N, Ridker PM. Effects of initiating insulin and metformin on glycemic control and inflammatory biomarkers among patients with type 2 diabetes: the LANCET randomized trial. JAMA. 2009;302(11):1186-1194.

59. Yki-Jarvinen H. Thiazolidinediones. N Engl J Med. 2004;351(11):1106-1118.

60. Cipolletta D, et al. PPAR- $\gamma$ is a major driver of the accumulation and phenotype of adipose tissue Treg cells. Nature. 2012;486(7404):549-553.

61. Vidal-Puig A, et al. Regulation of PPAR $\gamma$ gene expression by nutrition and obesity in rodents. JClin Invest. 1996;97(11):2553-2561.

62. Pfützner A, et al. Improvement of cardiovascular risk markers by pioglitazone is independent from glycemic control: results from the pioneer study. JAm Coll Cardiol. 2005;45(12):1925-1931.

63. DeFronzo RA, et al. Pioglitazone for diabetes prevention in impaired glucose tolerance. $N$ Engl JMed. 2011;364(12):1104-1115.

64. Kahn SE, et al. Glycemic durability of rosiglitazone, metformin, or glyburide monotherapy. N Engl J Med. 2006;355(23):2427-2443.

65. Cusi K, et al. Long-term pioglitazone treatment for patients with nonalcoholic steatohepatitis and prediabetes or type 2 diabetes mellitus: a randomized trial. Ann Intern Med. 2016;165(5):305-315.

66. Kernan WN, et al. Pioglitazone after ischemic stroke or transient ischemic attack. N Engl J Med. 2016;374(14):1321-1331.

67. Dormandy JA, et al. Secondary prevention of macrovascular events in patients with type 2 
diabetes in the PROactive Study (PROspective pioglitAzone Clinical Trial In macroVascular Events): a randomised controlled trial. Lancet. 2005;366(9493):1279-1289.

68. Home PD, et al. Rosiglitazone evaluated for cardiovascular outcomes in oral agent combination therapy for type 2 diabetes (RECORD): a multicentre, randomised, open-label trial. Lancet. 2009;373(9681):2125-2135.

69. Inzucchi SE, et al. Efficacy and metabolic effects of metformin and troglitazone in type II diabetes mellitus. N Engl J Med.1998;338(13):867-872.

70. Owen MR, Doran E, Halestrap AP. Evidence that metformin exerts its anti-diabetic effects through inhibition of complex 1 of the mitochondrial respiratory chain. Biochem J. 2000;348(pt 3):607-614.

71. Madiraju AK, et al. Metformin suppresses gluconeogenesis by inhibiting mitochondrial glycerophosphate dehydrogenase. Nature. 2014;510(7506):542-546.

72. Zhou G, et al. Role of AMP-activated protein kinase in mechanism of metformin action. JClin Invest. 2001;108(8):1167-1174.

73. Kelly B, Tannahill GM, Murphy MP, O'Neill LA. Metformin inhibits the production of reactive oxygen species from NADH:Ubiquinone oxidoreductase to limit induction of interleukin-1 $\beta$ (IL$1 \beta$ ) and boosts interleukin-10 (IL-10) in lipopolysaccharide (LPS)-activated macrophages. J Biol Chem. 2015;290(33):20348-20359.

74. Kim J, et al. Metformin suppresses lipopolysaccharide (LPS)-induced inflammatory response in murine macrophages via activating transcription factor-3 (ATF-3) induction. J Biol Chem. 2014;289(33):23246-23255.

75. Huang NL, Chiang SH, Hsueh CH, Liang YJ, Chen YJ, Lai LP. Metformin inhibits TNF- $\alpha-$

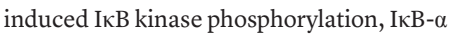
degradation and IL- 6 production in endothelial cells through PI3K-dependent AMPK phosphorylation. Int J Cardiol. 2009;134(2):169-175.

76. Morin-Papunen L, Rautio K, Ruokonen A, Hedberg P, Puukka M, Tapanainen JS. Metformin reduces serum C-reactive protein levels in women with polycystic ovary syndrome. JClin Endocrinol Metab. 2003;88(10):4649-4654.

77. De Jager J, et al. Effects of short-term treatment with metformin on markers of endothelial function and inflammatory activity in type 2 diabetes mellitus: a randomized, placebo-controlled trial. JIntern Med. 2005;257(1):100-109.

78. Caballero AE, et al. The differential effects of metformin on markers of endothelial activation and inflammation in subjects with impaired glucose tolerance: a placebo-controlled, randomized clinical trial. J Clin Endocrinol Metab. 2004;89(8):3943-3948.

79. Dandona P, et al. Increased plasma concentration of macrophage migration inhibitory factor (MIF) and MIF mRNA in mononuclear cells in the obese and the suppressive action of metformin. JClin Endocrinol Metab. 2004;89(10):5043-5047.

80. Kim SA, Choi HC. Metformin inhibits inflammatory response via AMPK-PTEN pathway in vascular smooth muscle cells. Biochem Biophys Res Commun. 2012;425(4):866-872.

81. Vasamsetti SB, Karnewar S, Kanugula AK, Thatipalli AR, Kumar JM, Kotamraju S. Metformin inhibits monocyte-to-macrophage differentiation via AMPK-mediated inhibition of STAT3 activation: potential role in atherosclerosis. Diabetes. 2015;64(6):2028-2041.

82. Drucker DJ, Nauck MA. The incretin system: glucagon-like peptide-1 receptor agonists and dipeptidyl peptidase- 4 inhibitors in type 2 diabetes. Lancet. 2006;368(9548):1696-1705.

83. Ohnuma K, Hosono O, Dang NH, Morimoto C. Dipeptidyl peptidase in autoimmune pathophysiology. Adv Clin Chem. 2011;53:51-84.

84. Sedo A, Duke-Cohan JS, Balaziova E, Sedova LR. Dipeptidyl peptidase IV activity and/or structure homologs: contributing factors in the pathogenesis of rheumatoid arthritis? Arthritis Res Ther. 2005;7(6):253-269.

85. Yazbeck R, Howarth GS, Abbott CA. Dipeptidyl peptidase inhibitors, an emerging drug class for inflammatory disease? Trends Pharmacol Sci. 2009;30(11):600-607.

86. Dai Y, Dai D, Wang X, Ding Z, Mehta JL. DPP-4 inhibitors repress NLRP3 inflammasome and interleukin-1beta via GLP-1 receptor in macrophages through protein kinase $\mathrm{C}$ pathway. Cardiovasc Drugs Ther. 2014;28(5):425-432.

87. Makdissi A, et al. Sitagliptin exerts an antinflammatory action. J Clin Endocrinol Metab. 2012;97(9):3333-3341.

88. Ussher JR, Drucker DJ. Cardiovascular biology of the incretin system. Endocr Rev. 2012;33(2):187-215.

89. Kim SC, et al. Postconditioning with a CpG containing oligodeoxynucleotide ameliorates myocardial infarction in a murine closed-chest model. Life Sci. 2014;119(1-2):1-8.

90. Green JB, et al. Effect of sitagliptin on cardiovascular outcomes in type 2 diabetes. $N$ Engl J Med. 2015;373(3):232-242.

91. Scirica BM, et al. Saxagliptin and cardiovascular outcomes in patients with type 2 diabetes mellitus. N EnglJMed. 2013;369(14):1317-1326.

92. White WB, et al. Alogliptin after acute coronary syndrome in patients with type 2 diabetes. N Engl J Med. 2013;369(14):1327-1335.

93. Chaudhuri A, et al. Exenatide exerts a potent antiinflammatory effect. J Clin Endocrinol Metab. 2012;97(1):198-207.

94. Marso SP, et al. Liraglutide and cardiovascular outcomes in type 2 diabetes. $N$ Engl J Med. 2016;375(4):311-322.

95. Marso SP, et al. Semaglutide cardiovascular outcomes in patients with type 2 diabetes. N Engl JMed. 2016;375:1834-1844.

96. Pfeffer MA, et al. Lixisenatide in patients with type 2 diabetes and acute coronary syndrome. N EnglJMed. 2015;373(23):2247-2257.

97. Barnett AH, et al. Efficacy and safety of empagliflozin added to existing antidiabetes treatment in patients with type 2 diabetes and chronic kidney disease: a randomised, double-blind, placebo-controlled trial. Lancet Diabetes Endocrinol. 2014;2(5):369-384.

98. Chilton R, et al. Effects of empagliflozin on blood pressure and markers of arterial stiffness and vascular resistance in patients with type 2 diabetes. Diabetes Obes Metab. 2015;17(12):1180-1193.

99. Ridderstråle $\mathrm{M}$, et al. Comparison of empagliflozin and glimepiride as add-on to metformin in patients with type 2 diabetes: a 104-week randomised, active-controlled, double-blind, phase 3 trial. Lancet Diabetes Endocrinol. 2014;2(9):691-700.

100.Honda Y, et al. The Selective SGLT2 Inhibitor Ipragliflozin Has a Therapeutic Effect on Nonalcoholic Steatohepatitis in Mice. PLoS One. 2016;11(1):e0146337.

101. Nakano S, et al. Remogliflozin etabonate improves fatty liver disease in diet-induced obese male mice. JClin Exp Hepatol. 2015;5(3):190-198.

102. Okamoto A, Yokokawa H, Sanada H, Naito T. Changes in levels of biomarkers associated with adipocyte function and insulin and glucagon kinetics during treatment with dapagliflozin among obese type 2 diabetes mellitus patients. Drugs R D. 2016;16(3):255-261.

103. Hawley SA, et al. The $\mathrm{Na}^{+} /$glucose co-transporter inhibitor canagliflozin activates AMP-activated protein kinase by inhibiting mitochondrial function increasing cellular AMP levels. Diabetes. 2016;65(9):2784-2794.

104.Zinman B, et al. Empagliflozin, cardiovascular outcomes, and mortality in type 2 diabetes. N Engl J Med. 2015;373(22):2117-2128.

105. Wanner C, et al. Empagliflozin and progression of kidney disease in type 2 diabetes. $\mathrm{N} \mathrm{EnglJ} \mathrm{Med.}$ 2016;375(4):323-334.

106.Mudaliar S, Alloju S, Henry RR. Can a shift in fuel energetics explain the beneficial cardiorenal outcomes in the EMPA-REG OUTCOME study? A unifying hypothesis. Diabetes Care. 2016;39(7):1115-1122.

107. Sattar N, McLaren J, Kristensen SL, Preiss D, McMurray JJ. SGLT2 inhibition and cardiovascular events: why did EMPA-REG Outcomes surprise and what were the likely mechanisms? Diabetologia. 2016;59(7):1333-1339.

108. Libby P, Ridker PM, Hansson GK. Progress and challenges in translating the biology of atherosclerosis. Nature. 2011;473(7347):317-325.

109.Libby P, Ridker PM, Hansson GK, Leducq Transatlantic Network on Atherothrombosis. Inflammation in atherosclerosis: from pathophysiology to practice. J Am Coll Cardiol. 2009;54(23):2129-2138.

110. Donath MY. Targeting inflammation in the treatment of type 2 diabetes: time to start. Nat Rev Drug Discov. 2014;13(6):465-476.

111. Ferrante AW. Macrophages, fat, and the emergence of immunometabolism. JClin Invest. 2013;123(12):4992-4993.

112. Odegaard JI, Chawla A. Pleiotropic actions of insulin resistance and inflammation in metabolic homeostasis. Science. 2013;339(6116):172-177.

113. Tabas I, Glass CK. Anti-inflammatory therapy in chronic disease: challenges and opportunities. Science. 2013;339(6116):166-172.

114. Ridker PM, Luscher TF. Anti-inflammatory therapies for cardiovascular disease. Eur Heart $J$. 2014;35(27):1782-1791.

115. Dinarello CA. Anti-inflammatory Agents: Present and Future. Cell. 2010;140(6):935-950.

116. Nakamura S, et al. Identification of baseline gene expression signatures predicting therapeutic responses to three biologic agents in rheumatoid arthritis: a retrospective observational study. Arthritis Res Ther. 2016;18:159.

117. Loll PJ, Picot D, Garavito RM. The structural basis of aspirin activity inferred from the crystal struc- 
ture of inactivated prostaglandin $\mathrm{H} 2$ synthase. Nat Struct Biol. 1995;2(8):637-643.

118. Morris HG, Sherman NA, McQuain C, Goldlust MB, Chang SF, Harrison LI. Effects of salsalate (nonacetylated salicylate) and aspirin on serum prostaglandins in humans. Ther Drug Monit. 1985;7(4):435-438.

119. Ryan JR, et al. Differential influences of salsalate, aspirin and naproxin on plasma renin activity and platelet thromboxane (TxB) 2 synthesis. In: Rainsford KD, Velo GP, eds. Side-Effects of Anti-Inflammatory Drugs: Part Two Studies In Major Organ Systems. Dordrecht, Netherlands: Springer Netherlands; 1987:445-446.

120. Ghalioungui P. Magic And Medical Science In Ancient Egypt. London, United Kingdom: Hodder \& Stoughton; 1963.

121. Kopp E, Ghosh S. Inhibition of NF-kB by sodium salicylate and aspirin. Science. 1994;265(5174):956-959.

122. Yin MJ, Yamamoto Y, Gaynor RB. The anti-inflammatory agents aspirin and salicylate inhibit the activity of IкB kinase- $\beta$. Nature. 1998;396(6706):77-80.

123. Yuan M, et al. Reversal of obesity- and diet-induced insulin resistance with salicylates or targeted disruption of Ikk $\beta$. Science. 2001;293(5535):1673-1677.

124. Alpert D, Vilcek J. Inhibition of IkappaB kinase activity by sodium salicylate in vitro does not reflect its inhibitory mechanism in intact cells. JBiol Chem. 2000;275(15):10925-10929.

125. Frantz B, O'Neill EA. The effect of sodium salicylate and aspirin on NF-kB. Science. 1995;270(5244):2017-2019.

126.Ebstein W. Zur therapie des diabetes mellitus, insbesondere uber die anwendeng der salicylauren natron bei demselben. Berliner Klinische Wochenschrift. 1876;13:337-340.

127. Goldfine $A B$, et al. Use of salsalate to target inflammation in the treatment of insulin resistance and type 2 diabetes. Clin Transl Sci. 2008;1(1):36-43.

128. Fleischman A, Shoelson SE, Bernier R, Goldfine AB. Salsalate improves glycemia and inflammatory parameters in obese young adults. Diabetes Care. 2008;31(2):289-294.

129. Faghihimani E, Aminorroaya A, Rezvanian $\mathrm{H}$, Adibi P, Ismail-Beigi F, Amini M. Reduction of insulin resistance and plasma glucose level by salsalate treatment in persons with prediabetes. Endocr Pract. 2012;18(6):826-833.

130. Faghihimani E, Aminorroaya A, Rezvanian $\mathrm{H}$, Adibi P, Ismail-Beigi F, Amini M. Salsalate improves glycemic control in patients with newly diagnosed type 2 diabetes. Acta Diabetol. 2013;50(4):537-543.

131. Goldfine $\mathrm{AB}$, et al. A randomised trial of salsalate for insulin resistance and cardiovascular risk factors in persons with abnormal glucose tolerance. Diabetologia. 2013;56(4):714-723.

132. Goldfine AB, et al. Salicylate (salsalate) in patients with type 2 diabetes: a randomized trial. Ann Intern Med. 2013;159(1):1-12.

133. Goldfine AB, et al. The effects of salsalate on glycemic control in patients with type 2 diabetes: a randomized trial. Ann Intern Med. 2010;152(6):346-357.
134. Pierce GL, Lesniewski LA, Lawson BR, Beske $\mathrm{SD}$, Seals DR. Nuclear factor-кB activation contributes to vascular endothelial dysfunction via oxidative stress in overweight/obese middle-aged and older humans. Circulation. 2009;119(9):1284-1292.

135. Goldfine $A B$, et al. Targeting inflammation using salsalate in patients with type 2 diabetes: effects on flow-mediated dilation (TINSAL-FMD). Diabetes Care. 2013;36(12):4132-4139.

136. Nohria A, et al. The effect of salsalate therapy on endothelial function in a broad range of subjects. JAm Heart Assoc. 2014;3(1):e000609.

137. Gupta SK, et al. Improvement in HIV-related endothelial dysfunction using the anti-inflammatory agent salsalate: a pilot study. AIDS 2008;22(5):653-655.

138. Hauser TH, et al. Effect of targeting inflammation with salsalate: The TINSAL-CVD randomized clinical trial on progression of coronary plaque in overweight and obese patients using statins. JAMA Cardiol. 2016;1(4):413-423.

139. Hawley SA, et al. The ancient drug salicylate directly activates AMP-activated protein kinase. Science. 2012;336(6083):918-922.

140. Hundal RS, et al. Mechanism by which high-dose aspirin improves glucose metabolism in type 2 diabetes. JClin Invest. 2002;109(10):1321-1326.

141. Penesova A, Koska J, Ortega E, Bunt JC, Bogardus C, de Courten B. Salsalate has no effect on insulin secretion but decreases insulin clearance: a randomized, placebo-controlled trial in subjects without diabetes. Diabetes Obes Metab. 2015;17(6):608-612.

142. Bai A, et al. AMPK agonist downregulates innate and adaptive immune responses in TNBS-induced murine acute and relapsing colitis. Biochem Pharmacol. 2010;80(11):1708-1717.

143. Zhao X, et al. Activation of AMPK attenuates neutrophil proinflammatory activity and decreases the severity of acute lung injury. Am J Physiol Lung Cell Mol Physiol. 2008;295(3):L497-L504.

144. Everett BM, et al. Rationale and design of the Cardiovascular Inflammation Reduction Trial: a test of the inflammatory hypothesis of atherothrombosis. Am Heart J. 2013;166(2):199-207.e15.

145. Cronstein BN, Naime D, Ostad E. The antiinflammatory mechanism of methotrexate. Increased adenosine release at inflamed sites diminishes leukocyte accumulation in an in vivo model of inflammation. JClin Invest. 1993;92(6):2675-2682.

146.Pirkmajer S, et al. Methotrexate promotes glucose uptake and lipid oxidation in skeletal muscle via AMPK activation. Diabetes. 2015;64(2):360-369.

147. Hasko G, Cronstein B. Regulation of inflammation by adenosine. Front Immunol. 2013;4:85.

148. Andersson $\mathrm{O}$, et al. Adenosine signaling promotes regeneration of pancreatic $\beta$ cells in vivo. Cell Metab. 2012;15(6):885-894.

149. Annes JP, et al. Adenosine kinase inhibition selectively promotes rodent and porcine islet $\beta$-cell replication. Proc Natl Acad Sci U S A. 2012;109(10):3915-3920.

150. Russo GT, et al. Methotrexate increases skeletal muscle GLUT4 expression and improves metabolic control in experimental diabetes. J Nutr Metab. 2012;2012:132056.

151. DeOliveira CC, et al. Effects of methotrexate on inflammatory alterations induced by obesity: an in vivo and in vitro study. Mol Cell Endocrinol. 2012;361(1-2):92-98.

152. Bulgarelli A, Martins Dias AA, Caramelli B, Maranhão RC. Treatment with methotrexate inhibits atherogenesis in cholesterol-fed rabbits. J Cardiovasc Pharmacol. 2012;59(4):308-314.

153. Choi HK, Hernán MA, Seeger JD, Robins JM, Wolfe F. Methotrexate and mortality in patients with rheumatoid arthritis: a prospective study. Lancet. 2002;359(9313):1173-1177.

154. Naranjo A, et al. Cardiovascular disease in patients with rheumatoid arthritis: results from the QUEST-RA study. Arthritis Res Ther. 2008;10(2):R30.

155. Prodanovich S, Ma F, Taylor JR, Pezon C, Fasihi $\mathrm{T}$, Kirsner RS. Methotrexate reduces incidence of vascular diseases in veterans with psoriasis or rheumatoid arthritis. JAm Acad Dermatol. 2005;52(2):262-267.

156. Solomon DH, et al. Immunosuppressive medications and hospitalization for cardiovascular events in patients with rheumatoid arthritis. Arthritis Rheum. 2006;54(12):3790-3798.

157. van Halm VP, Nurmohamed MT, Twisk JW, Dijkmans BA, Voskuyl AE. Disease-modifying antirheumatic drugs are associated with a reduced risk for cardiovascular disease in patients with rheumatoid arthritis: a case control study. Arthritis Res Ther. 2006;8(5):R151.

158. de Rotte MC, et al. Effect of methotrexate use and erythrocyte methotrexate polyglutamate on glycosylated hemoglobin in rheumatoid arthritis. Arthritis Rheumatol. 2014;66(8):2026-2036.

159. Ofei F, Hurel S, Newkirk J, Sopwith M, Taylor R. Effects of an engineered human anti-TNF- $\alpha$ antibody (CDP571) on insulin sensitivity and glycemic control in patients with NIDDM. Diabetes. 1996;45(7):881-885.

160.Paquot N, Castillo MJ, Lefèbvre PJ, Scheen AJ. No increased insulin sensitivity after a single intravenous administration of a recombinant human tumor necrosis factor receptor: Fc fusion protein in obese insulin-resistant patients. J Clin Endocrinol Metab. 2000;85(3):1316-1319.

161. Dominguez H, et al. Metabolic and vascular effects of tumor necrosis factor-alpha blockade with etanercept in obese patients with type 2 diabetes. J Vasc Res. 2005;42(6):517-525.

162. Bernstein LE, Berry J, Kim S, Canavan B, Grinspoon SK. Effects of etanercept in patients with the metabolic syndrome. Arch Intern Med. 2006;166(8):902-908.

163. Yazdani-Biuki B, et al. Improvement of insulin sensitivity in insulin resistant subjects during prolonged treatment with the anti-TNF-alpha antibody infliximab. Eur JClin Invest. 2004;34(9):641-642.

164. Kiortsis DN, Mavridis AK, Vasakos S, Nikas SN, Drosos AA. Effects of infliximab treatment on insulin resistance in patients with rheumatoid arthritis and ankylosing spondylitis. Ann Rheum Dis. 2005;64(5):765-766.

165. Yazdani-Biuki B, Mueller T, Brezinschek HP, Hermann J, Graninger W, Wascher TC. Relapse of diabetes after interruption of chronic administration of anti-tumor necrosis factor-alpha antibody infliximab: a case observation. Diabetes Care. 
2006;29(7):1712-1713.

166. Gonzalez-Gay MA, et al. Anti-tumor necrosis factor-alpha blockade improves insulin resistance in patients with rheumatoid arthritis. Clin Exp Rheumatol. 2006;24(1):83-86.

167. Huvers FC, Popa C, Netea MG, van den Hoogen FH, Tack CJ. Improved insulin sensitivity by anti-TNF- $\alpha$ antibody treatment in patients with rheumatic diseases. Ann Rheum Dis. 2007;66(4):558-559.

168. Marra M, et al. Effect of etanercept on insulin sensitivity in nine patients with psoriasis. Int $J$ Immunopathol Pharmacol. 2007;20(4):731-736.

169. Timper K, Hruz P, Beglinger C, Donath MY. Infliximab in the treatment of Crohn disease and type 1 diabetes. Diabetes Care. 2013;36(7):e90-e91.

170.Stanley TL, et al. TNF- $\alpha$ antagonism with etanercept decreases glucose and increases the proportion of high molecular weight adiponectin in obese subjects with features of the metabolic syndrome. JClin Endocrinol Metab. 2011;96(1):E146-E150.

171. Zhu W, et al. Interleukin receptor activates a MYD88-ARNO-ARF6 cascade to disrupt vascular stability. Nature. 2012;492(7428):252-255.

172. Dinarello CA, van der Meer JW. Treating inflammation by blocking interleukin-1 in humans. Semin Immunol. 2013;25(6):469-484.

173. Agostini L, Martinon F, Burns K, McDermott MF, Hawkins PN, Tschopp J. NALP3 forms an IL-1 $\beta$-processing inflammasome with increased activity in Muckle-Wells autoinflammatory disorder. Immunity. 2004;20(3):319-325.

174. Martinon F, Mayor A, Tschopp J. The inflammasomes: guardians of the body. Annu Rev Immunol. 2009;27:229-265.

175. Schroder K, Tschopp J. The inflammasomes. Cell. 2010;140(6):821-832

176. Koenen TB, et al. Hyperglycemia activates caspase- 1 and TXNIP-mediated IL- $1 \beta$ transcription in human adipose tissue. Diabetes. 2011;60(2):517-524.

177. Vandanmagsar B, et al. The NLRP3 inflammasome instigates obesity-induced inflammation and insulin resistance. Nat Med. 2011;17(2):179-188.

178. Maedler K, et al. Glucose-induced $\beta$ cell production of IL-1beta contributes to glucotoxicity in human pancreatic islets. J Clin Invest. 2002;110(6):851-860.

179. Larsen CM, Faulenbach M, Vaag A, Ehses JA, Donath MY, Mandrup-Poulsen T. Sustained effects of interleukin-1 receptor antagonist treatment in type 2 diabetes. Diabetes Care. 2009;32(9):1663-1668.

180. Larsen CM, et al. Interleukin-1-receptor antagonist in type 2 diabetes mellitus. $N$ Engl J Med 2007;356(15):1517-1526.

181. van Asseldonk EJ, Stienstra R, Koenen TB, Joosten LA, Netea MG, Tack CJ. Treatment with Anakinra improves disposition index but not insulin sensitivity in nondiabetic subjects with the metabolic syndrome: a randomized, double-blind, placebo-controlled study. JClin Endocrinol Metab. 2011;96(7):2119-2126.
182. Cavelti-Weder C, et al. Effects of gevokizumab on glycemia and inflammatory markers in type 2 diabetes. Diabetes Care. 2012;35(8):1654-1662.

183. Hensen J, Howard CP, Walter V, Thuren T. Impact of interleukin-1 $\beta$ antibody (canakinumab) on glycaemic indicators in patients with type 2 diabetes mellitus: results of secondary endpoints from a randomized, placebo-controlled trial. Diabetes Metab. 2013;39(6):524-531.

184. Rissanen A, et al. Effect of anti-IL-1 $\beta$ antibody (canakinumab) on insulin secretion rates in impaired glucose tolerance or type 2 diabetes: results of a randomized, placebo-controlled trial. Diabetes Obes Metab. 2012;14(12):1088-1096.

185. Sloan-Lancaster J, et al. Double-blind, randomized study evaluating the glycemic and anti-inflammatory effects of subcutaneous LY2189102, a neutralizing IL-1 $\beta$ antibody, in patients with type 2 diabetes. Diabetes Care. 2013;36(8):2239-2246

186.Böni-Schnetzler M, et al. Increased interleukin (IL)-1 $\beta$ messenger ribonucleic acid expression in $\beta$-cells of individuals with type 2 diabetes and regulation of IL-1 $\beta$ in human islets by glucose and autostimulation. J Clin Endocrinol Metab. 2008;93(10):4065-4074.

187. van Popper PCM, Van Asseldonk EVA, Netea MG, Tack CJ. The interleukin-1 receptor antag onist anakinra improves beta cell function in subjects with impaired glucose tolerance. 49th Annual Meeting of the European Association for the Study of Diabetes. Abstract 739. 2013.

188. Dinarello CA. Immunological and inflammatory functions of the interleukin-1 family. Annu Rev Immunol. 2009;27:519-550.

189. Fearon WF, Fearon DT. Inflammation and cardiovascular disease: role of the interleukin-1 receptor antagonist. Circulation. 2008;117(20):2577-2579.

190. Galea J, Armstrong J, Gadsdon P, Holden H, Francis SE, Holt CM. Interleukin-1 $\beta$ in coronary arteries of patients with ischemic heart disease. Arterioscler Thromb Vasc Biol. 1996;16(8):1000-1006.

191. Geng YJ, Libby P. Evidence for apoptosis in advanced human atheroma. Colocalization with interleukin-1 $\beta$-converting enzyme. Am J Pathol. 1995;147(2):251-266.

192. Ridker PM, et al. Effects of interleukin-1 $\beta$ inhibition with canakinumab on hemoglobin A1c, lipids, C-reactive protein, interleukin-6, and fibrinogen: a phase IIb randomized, placebo-controlled trial. Circulation. 2012;126(23):2739-2748.

193. Ridker PM, Thuren T, Zalewski A, Libby P. Interleukin-1 $\beta$ inhibition and the prevention of recurrent cardiovascular events: rationale and design of the Canakinumab Anti-inflammatory Thrombosis Outcomes Study (CANTOS). Am Heart J. 2011;162(4):597-605.

194. Feuerer M, et al. Lean, but not obese, fat is enriched for a unique population of regulatory $\mathrm{T}$ cells that affect metabolic parameters. Nat Med. 2009;15(8):930-939.

195. Luster AD, Alon R, von Andrian UH. Immune cell migration in inflammation: present and future therapeutic targets. Nat Immunol. 2005;6(12):1182-1190.

196. Luster AD, Alon R, von Andrian UH. Immune cell migration in inflammation: present and future therapeutic targets. Nat Immunol. 2005;6(12):1182-1190.

197. Peters-Golden M, Henderson WR Jr. Leukotrienes. N Engl JMed. 2007;357(18):1841-1854.

198.Shimizu T. Lipid mediators in health and disease: enzymes and receptors as therapeutic targets for the regulation of immunity and inflammation. Annu Rev Pharmacol Toxicol. 2009;49:123-150.

199. Weisberg SP, et al. CCR2 modulates inflammatory and metabolic effects of high-fat feeding. J Clin Invest. 2006;116(1):115-124.

200.Kanda H, et al. MCP-1 contributes to macrophage infiltration into adipose tissue, insulin resistance, and hepatic steatosis in obesity. JClin Invest. 2006;116(6):1494-1505

201. Kamei N, et al. Overexpression of monocyte che moattractant protein-1 in adipose tissues causes macrophage recruitment and insulin resistance. J Biol Chem. 2006;281(36):26602-26614.

202.Hsieh PS, Lu KC, Chiang CF, Chen CH. Suppressive effect of COX2 inhibitor on the progression of adipose inflammation in high-fat-induced obese rats. Eur JClin Invest. 2010;40 (2):164-171.

203. Hsieh PS, et al. Selective COX2 inhibition improves whole body and muscular insulin resistance in fructose-fed rats. Eur JClin Invest. 2008;38(11):812-819

204.Gislason GH, et al. Risk of death or reinfarction associated with the use of selective cyclooxygenase- 2 inhibitors and nonselective nonsteroidal antiinflammatory drugs after acute myocardial infarction. Circulation. 2006;113(25):2906-2913.

205. Kearney PM, Baigent C, Godwin J, Halls H, Emberson JR, Patrono C. Do selective cyclo-oxygenase- 2 inhibitors and traditional non-steroidal anti-inflammatory drugs increase the risk of atherothrombosis? Meta-analysis of randomised trials. BMJ. 2006;332(7553):1302-1308.

206.Solomon SD, et al. Cardiovascular risk associated with celecoxib in a clinical trial for colorectal adenoma prevention. $\mathrm{NEnglJMed}$. 2005;352(11):1071-1080.

207. Graffouillère L, et al. Prospective association between the Dietary Inflammatory Index and mortality: modulation by antioxidant supplementation in the SU.VI.MAX randomized controlled trial. Am J Clin Nutr. 2016;103(3):878-885.

208. Ruiz-Canela M, Bes-Rastrollo M, MartínezGonzález MA. The role of dietary inflammatory index in cardiovascular disease, metabolic syndrome and mortality. Int JMol Sci. 2016;17(8):E1265.

209.Utzschneider KM, Kratz M, Damman CJ, Hullarg M. Mechanisms linking the gut microbiome and glucose metabolism. JClin Endocrinol Metab. 2016;101(4):1445-1454.

210. Vrieze A, et al. Transfer of intestinal microbiota from lean donors increases insulin sensitivity in individuals with metabolic syndrome. Gastroenterology. 2012;143(4):913-916.e7. 